\title{
Peak oxygen uptake in relation to total heart volume discriminates heart failure patients from healthy volunteers and athletes
}

\author{
Henrik Engblom¹, Katarina Steding ${ }^{1}$, Marcus Carlsson ${ }^{1}$, Henrik Mosén ${ }^{1}$, Bo Hedén ${ }^{1}$, Torsten Buhre², Björn Ekmehag ${ }^{3}$,
} Håkan Arheden ${ }^{1 *}$

\begin{abstract}
Background: An early sign of heart failure (HF) is a decreased cardiac reserve or inability to adequately increase cardiac output during exercise. Under normal circumstances maximal cardiac output is closely related to peak oxygen uptake $\left(\mathrm{VO}_{2}\right.$ peak) which has previously been shown to be closely related to total heart volume (THV). Thus, the aim of this study was to derive a $\mathrm{VO}_{2}$ peak/THV ratio and to test the hypothesis that this ratio can be used to distinguish patients with HF from healthy volunteers and endurance athletes. Thirty-one patients with HF of different etiologies were retrospectively included and 131 control subjects (60 healthy volunteers and 71 athletes) were prospectively enrolled. Peak oxygen uptake was determined by maximal exercise test and THV was determined by cardiovascular magnetic resonance. The $\mathrm{VO}_{2}$ peak $/ \mathrm{THV}$ ratio was then derived and tested.

Results: Peak oxygen uptake was strongly correlated to THV $\left(r^{2}=0.74, p<0.001\right)$ in the control subjects, but not for the patients $\left(r^{2}=0.0002, p=0.95\right)$. The $\mathrm{VO}_{2}$ peak/THV ratio differed significantly between control subjects and patients, even in patients with normal ejection fraction and after normalizing for hemoglobin levels $(p<0.001)$. In a multivariate analysis the $\mathrm{VO}_{2}$ peak/THV ratio was the only independent predictor of presence of $\mathrm{HF}(\mathrm{p}<0.001)$.

Conclusions: The $\mathrm{VO}_{2}$ peak/THV ratio can be used to distinguish patients with clinically diagnosed HF from healthy volunteers and athletes, even in patients with preserved systolic left ventricular function and after normalizing for hemoglobin levels.
\end{abstract}

\section{Introduction}

Heart failure (HF) is a complex syndrome associated with a variety of etiologies and clinical presentations [1] which implies a major diagnostic challenge. The accuracy of diagnosis by clinical means alone is often inadequate $[2,3]$. According to the definition of HF, patients should exhibit typical symptoms or signs such as breathlessness or fatigue at rest or during exercise, pulmonary congestion or ankle swelling, and objective evidence of cardiac dysfunction at rest [1]. However, ACC/AHA have identified 4 stages (A-D) with emphasis on the evolution and progression of HF, where stage A defines patients who are at high risk for developing HF but has no structural disorder of the heart and no signs or

\footnotetext{
* Correspondence: hakan.arheden@med.lu.se

'Dept of Clinical Physiology, Lund University and Skåne University Hospital, Lund, Sweden

Full list of author information is available at the end of the article
}

symptoms of HF [4]. Thus, there is a need for diagnostic methods that can objectify early signs of decreased cardiac performance in order to optimize management and treatment to prevent or delay progression of the disease and consequently improve patient prognosis.

Cardiac performance can be assessed by maximal exercise testing with measurements of respiratory gas exchange to determine peak oxygen uptake $\left(\mathrm{VO}_{2}\right.$ peak), shown to be closely correlated to maximal cardiac output $[5,6]$. This method is predominantly used in evaluation of patients with established HF under consideration for heart transplantation $[7,8]$. Experimental animal studies $[9,10]$ and a recent study in humans [11] have shown that $\mathrm{VO}_{2}$ peak is closely correlated to the total heart volume (THV). Hence, a physiologically enlarged heart has a proportionally increased $\mathrm{VO}_{2}$ peak. A decreased cardiac reserve and inability to increase cardiac output to

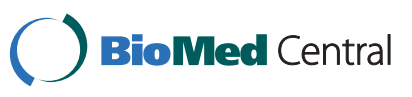


meet the metabolic requirements during exercise might be the first sign of HF [12].

Cardiovascular magnetic resonance (CMR) is well suited for determination of the THV, given the completely three dimensional nature of the technique. CMR is also considered the gold standard for determination of cardiac function and dimensions [13].

Therefore, the aim of this study was to use maximal exercise testing with measurements of respiratory gas exchange and CMR to derive a $\mathrm{VO}_{2}$ peak/THV-index as a novel measure of the cardiac reserve and to test if this can be used to distinguish patients with HF from healthy volunteers and endurance athletes with physiologically enlarged hearts.

\section{Methods}

\section{Study population and design}

This study follows the Declaration of Helsinki and was approved by the regional ethics committee. All study subjects gave their informed consent to participate in the study.

Thirty-one patients (5 females) who had been clinically diagnosed with HF with varying etiology were retrospectively enrolled and compared with 60 healthy volunteers (20 females) from the local community and 71 elite athletes (30 soccer players [12 females], 23 European handball players [12 females] and 18 triathletes [ 6 females]) prospectively enrolled in the study. All underwent both CMR and maximal incremental exercise testing on ergometer cycle, with measurement of respiratory gas exchange, within a month for the patients and within a week for the healthy volunteers and athletes. Hemoglobin level was assessed within 2 weeks of the exercise test in patients and on the day of the exercise test in healthy volunteers and athletes who gave their consent for blood sampling.

\section{CMR and analysis}

CMR was performed on a $1.5 \mathrm{~T}$ system (Philips Intera CV; Philips, Best, The Netherlands) with a cardiac synergy coil. All subjects were placed in supine position. Cine short-axis gradient-recalled echo images covering the entire heart from base of the atria to the ventricular apex were acquired using a steady state free precession sequence - slice thickness $=8 \mathrm{~mm}$, field-of-view $=340 \mathrm{~mm}$, repetition time $=3.14 \mathrm{~ms}$, echo time $=1.58 \mathrm{~ms}$.

For viability assessment in the patients, late gadolinium enhancement (LGE) images were acquired 20-30 minutes after intravenous injection of an extracellular gadolinium-based contrast agent (gadoteric acid, Gd-DOTA, $0.2 \mathrm{mmol} / \mathrm{kg}$, Guerbet, Gothia Medical AB, Billdal, Sweden). An inversion-recovery (IR) sequence was applied in the corresponding short-axis planes as for the cine images. Typical IR sequence parameters were: slice thickness $=8 \mathrm{~mm}$, repetition time $=3.9 \mathrm{~ms}$, echo time $=1.2 \mathrm{~ms}$, in-plane resolution $=1.5 \times 1.5 \mathrm{~mm}$ and flip angle $=15^{\circ}$ with acquisition every heartbeat. The inversion time, typically $200-300 \mathrm{~ms}$, was manually adjusted to null the signal from remote myocardium [14]. Volumetric measurements

Total heart volume was measured in the cine short-axis images by planimetry as previously described [15]. In short, THV was defined as the volume of all structures within the pericardium, including myocardium, blood pool, atria and pericardial fluid. This also includes the proximal parts of the great vessels covered by the pericardium. A region of interest was manually drawn around the pericardial border in all the short-axis images of the heart in end-diastole (Figure 1) using a freely available software (Segment 1.697; http://segment. heiberg.se) [16]. The summed area was then multiplied with slice thickness to obtain THV. The volumetric method used to determine THV has previously been applied in studies of cardiac pumping mechanics [15,17-21].

Furthermore, endocardial borders of the left ventricular (LV) myocardium were manually delineated in end-diastolic and end-systolic short-axis images, enabling calculation of LV end-diastolic and end-systolic volumes (LVEDV and LVESV) as well as LV ejection fraction (LVEF). In addition, the epicardial borders of the left ventricle were delineated for determination of LV mass (LVM).

\section{Viability assessment}

Myocardial scar/fibrosis was assessed by manual delineation of the hyperenhanced myocardium in the LGE short-axis images.

\section{Exercise test with respiratory gas analysis}

A maximal incremental exercise test was performed using an electronically braked cycle ergometer (Siemens Ergomed 940, Upplands Väsby, Sweden) with respiratory gas analysis equipment (Oxycon Champion, Jaeger, Hochberg, Germany). The test protocols were chosen to yield exercise duration of approximately 8-12 minutes, yielding starting stress between $10-150 \mathrm{~W}$ with $10-30 \mathrm{~W}$ increment per minute. Peak oxygen uptake was defined as the highest value reached at the end of exercise and expressed both as $\mathrm{ml} \mathrm{min}^{-1}$ ( $\mathrm{VO}_{2}$ peak) and $\mathrm{ml} \mathrm{min}^{-1} \mathrm{~kg}^{-1}$ $\left(\mathrm{VO}_{2}\right.$ peak $\left._{\mathrm{kg}}\right)$.

A 12-lead ECG was acquired throughout the test. Blood pressure was measured by sphygmanometer in the supine position before exercise, every two minutes during exercise on the ergometer cycle and in the supine position at rest after exercise.

\section{$\mathrm{VO}_{2}$ peak/THV ratio}

A ratio between $\mathrm{VO}_{2}$ peak and THV was derived. Furthermore, the ratio was also normalized to hemoglobin levels 


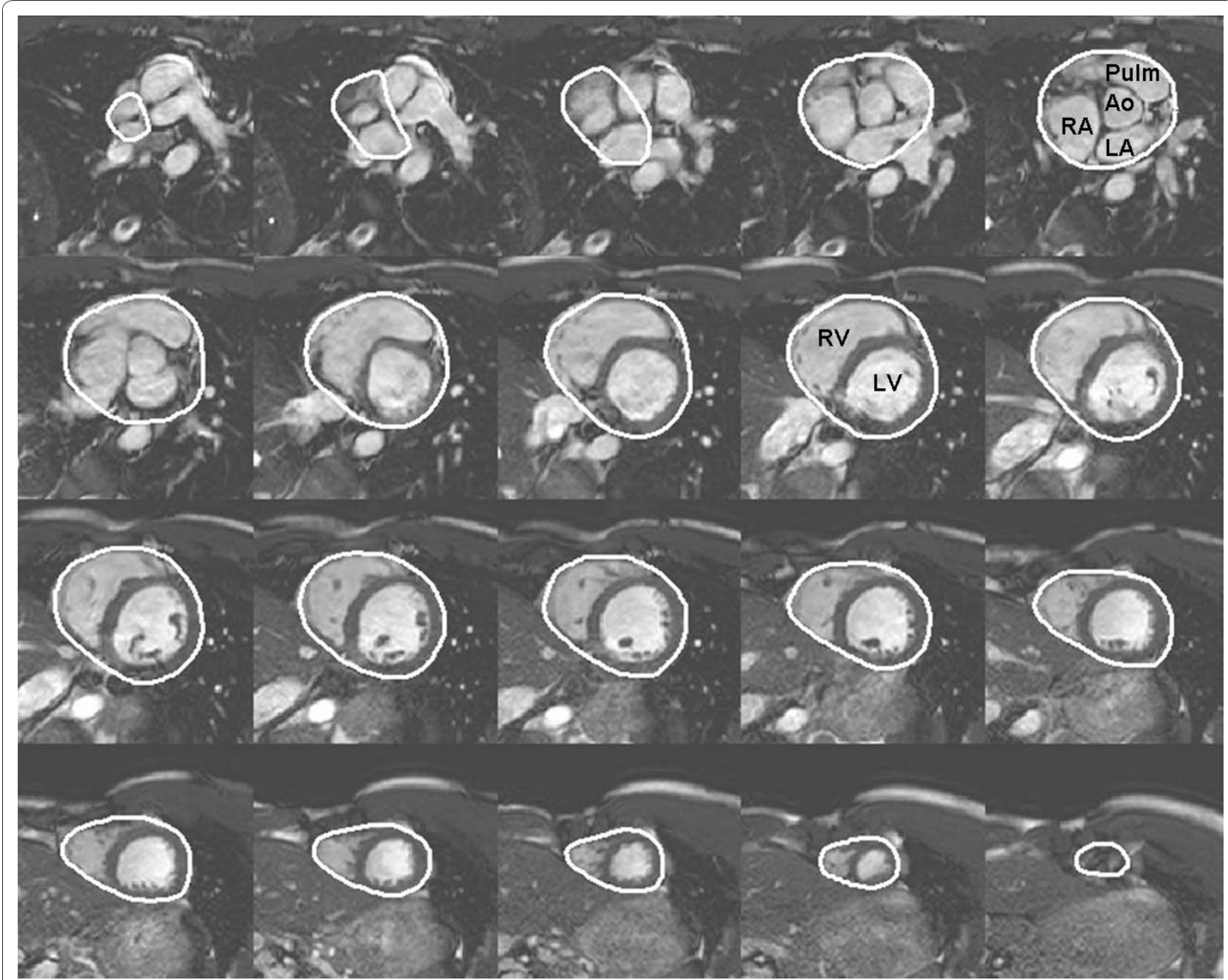

Figure 1 Delineation of total heart volume. Example of delineation of the pericardium from short-axis cardiac magnetic resonance images enabling determination of the total heart volume. The base is seen in the upper left corner and apex in the lower right corner. Ao = ascending aorta, $\mathrm{LA}=$ left atrium, $\mathrm{LV}=$ left ventricle, Pulm = pulmonary artery, $\mathrm{RA}=$ right atrium, $\mathrm{RV}=$ right ventricle.

to partly compensate for differences in oxygen delivery capacity in peripheral tissue in the presence of anemia. The $\mathrm{VO}_{2}$ peak/THV ratio was also compared to levels of plasma amino terminal pro-brain natriuretic peptide (pro-BNP) for the patients who had a pro-BNP taken within 4 months of the exercise test.

\section{Statistical analysis}

Values are shown as mean \pm standard deviation. Univariate linear regression analysis was used to assess the correlation between $\mathrm{VO}_{2}$ peak and THV as well as body weight. Unpaired T-test was used to assess differences between variables where normal distribution was assumed. The Mann-Whitney test was used to assess differences where normal distribution could not be assumed. Forward stepwise multivariate regression analysis was performed to assess the independent predictive values of THV, LVEF, LVEDV, $\mathrm{VO}_{2}$ peak, $\mathrm{VO}_{2}$ peak $\mathrm{kg}_{\mathrm{kg}}$ and the $\mathrm{VO}_{2}$ peak/THV ratio for presence of HF. Receiver operating characteristic (ROC) analysis was performed to test the ability of the $\mathrm{VO}_{2}$ peak/THV ratio to distinguish between HF patients and controls. All statistical analysis was performed using SPSS 16.0 (Chicago, IL, USA). A p-value of $<0.05$ was considered statistically significant.

\section{Results}

Subject characteristics are seen in Table 1. Twelve patients had been diagnosed with dilated cardiomyopathy, five patients with ischemic cardiomyopathy, three patients with suspected myocardial hemocromatosis, two patients with hypertrophic cardiomyopathy, two patients with congenital heart disease, two patients with constrictive cardiomyopathy, one patient with post-partum cardiomyopathy, 
Table 1 Patient characteristics

\begin{tabular}{|c|c|c|c|}
\hline & $\begin{array}{c}\text { Healthy } \\
\text { volunteers }\end{array}$ & Athletes & Patients \\
\hline Number & $n=60$ & $\mathrm{n}=71$ & $\mathrm{n}=31$ \\
\hline Gender (M/F) & $40 / 20$ & $41 / 30$ & $26 / 5$ \\
\hline Age (years) & $35 \pm 11$ & $26 \pm 7^{* * *}$ & $54 \pm 12^{* * *}$ \\
\hline Weight (kg) & $75 \pm 11$ & $75 \pm 11$ & $80 \pm 15$ \\
\hline Height (m) & $1.77 \pm 0.08$ & $1.78 \pm 0.08$ & $1.74 \pm 0.08$ \\
\hline SBP $(\mathrm{mmHg})$ & $127 \pm 9$ & $126 \pm 9$ & $107 \pm 12^{* * *}$ \\
\hline $\mathrm{DBP}(\mathrm{mmHg})$ & $74 \pm 8$ & $72 \pm 8$ & $69 \pm 9^{* *}$ \\
\hline $\mathrm{VO}_{2}$ peak $\left(\mathrm{ml} \mathrm{min}{ }^{-1}\right)$ & $3102 \pm 696$ & $\begin{array}{l}3866 \pm \\
747^{* * *}\end{array}$ & $\begin{array}{l}1309 \pm \\
430^{* * * *}\end{array}$ \\
\hline $\begin{array}{l}\mathrm{VO}_{2} \text { peak }_{\mathrm{kg}}\left(\mathrm{ml} \mathrm{min}{ }^{-1}\right. \\
\left.\mathrm{kg}^{-1}\right)\end{array}$ & $41 \pm 7$ & $52 \pm 7^{* * *}$ & $16 \pm 5^{* * *}$ \\
\hline LVEDV (ml) & $183 \pm 31$ & $223 \pm 39^{* * *}$ & $\begin{array}{l}280 \pm \\
132^{* * *}\end{array}$ \\
\hline LVM (g) & $105 \pm 25$ & $130 \pm 34^{* * *}$ & $177 \pm 87^{* * *}$ \\
\hline THV (ml) & $793 \pm 128$ & $\begin{array}{l}947 \pm \\
169^{* * *}\end{array}$ & $\begin{array}{l}1201 \pm \\
460^{* * *}\end{array}$ \\
\hline LVEF (\%) & $62 \pm 6$ & $58 \pm 6^{* *}$ & $37 \pm 22^{* * *}$ \\
\hline
\end{tabular}

$\mathrm{DBP}=$ diastolic blood pressure, LVEDV = left ventricular end-diastolic volume, $\mathrm{LVEF}=$ left ventricular ejection fraction, $\mathrm{LVM}=$ left ventricular mass, SBP $=$ systolic blood pressure, $\mathrm{THV}=$ total heart volume, $\mathrm{VO}_{2}$ peak = peak oxygen uptake, ${ }^{* *} \mathrm{p}<0.01,{ }^{* * *} \mathrm{p}<0.001$ compared to the healthy volunteers.

one patient with drug-induced cardiomyopathy, and three patients with HF of unknown cause. In $16 \%(5 / 31)$ of the patients there were signs of scarred/fibrous myocardium on the LGE images. Hemoglobin levels were assessed the same day as the exercise test in 65\% (39/60) of the healthy volunteers and in $73 \%(52 / 71)$ of 71 athletes (hemoglobin levels were not assessed in the triathletes) and within 2 weeks of the exercise test in $97 \%(30 / 31)$ of the patients.
The inter-observer variabililty for measuring THV was $-5 \pm 37 \mathrm{ml}\left(\mathrm{r}^{2}=0.96, \mathrm{p}<0.001\right)$.

\section{Peak oxygen uptake vs cardiac characteristics and body weight}

There was a strong correlation $\left(\mathrm{r}^{2}=0.74, \mathrm{p}<0.001\right)$ between $\mathrm{VO}_{2}$ peak and THV for the control subjects (healthy volunteers and athletes) but no correlation $\left(\mathrm{r}^{2}=\right.$ $0.0002, \mathrm{p}=0.95$ ) for HF patients (Figure $2 \mathrm{~A}$ ). Figure $2 \mathrm{~B}$ shows only a moderate correlation $\left(\mathrm{r}^{2}=0.37, \mathrm{p}<0.001\right)$ between $\mathrm{VO}_{2}$ peak and body weight in the control subjects with a considerable variation in $\mathrm{VO}_{2}$ peak for a given body weight.

Even though a significant difference in LVEF was found between the control subjects and the HF patients $(\mathrm{p}<0.001$; Figure 3A), there was a significant overlap with $29 \%(9 / 31)$ of the HF patient examinations showing LVEF > 50\%. Figure 3B shows a comparison between control subjects and HF patients with LVEF > 50\%, where the HF patients had a slightly higher LVEF ( $\mathrm{p}=$ 0.04). Despite the higher LVEF in these patients, the $\mathrm{VO}_{2}$ peak/THV ratio was significantly lower compared to the control subjects ( $\mathrm{p}<0.001$; Figure $3 \mathrm{C}$ ).

\section{$\mathrm{VO}_{2}$ peak/THV ratio}

Figure 4A shows the $\mathrm{VO}_{2}$ peak/THV ratio for each subject group. The HF patients showed a significantly lower $\mathrm{VO}_{2}$ peak/THV ratio $(\mathrm{p}<0.001)$ than the other subject groups, even after normalizing for hemoglobin levels ( $\mathrm{p}<0.001$, Figure 4B).

When dividing the different subgroups with regard to $\mathrm{VO}_{2}$ peak alone, there was still a significant difference between healthy volunteers and HF patients (3102 \pm 696
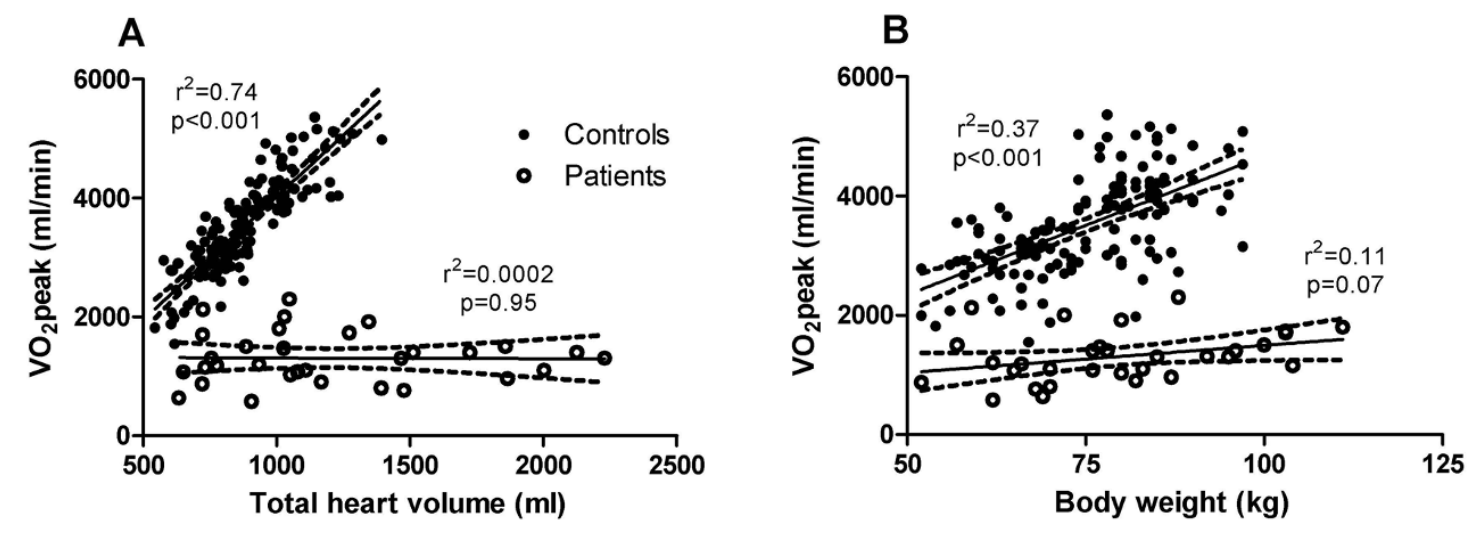

Figure 2 Peak oxygen uptake in relation to total heart volume and body weight. Peak oxygen uptake $\left(\mathrm{VO}_{2}\right.$ peak) in comparison to A) total heart volume (THV) and B) body weight. Filled circles denote control subjects, including healthy volunteers and athletes and open circles denote heart failure patients. Solid lines represent the regression line and dashed lines the $95 \%$ confidence interval. In the control group there was a strong correlation between $\mathrm{VO}_{2}$ peak and THV. Even though there was also a significant correlation between $\mathrm{VO}_{2}$ peak and body weight, there was a considerable variation of $\mathrm{VO}_{2}$ peak for a given body weight. 

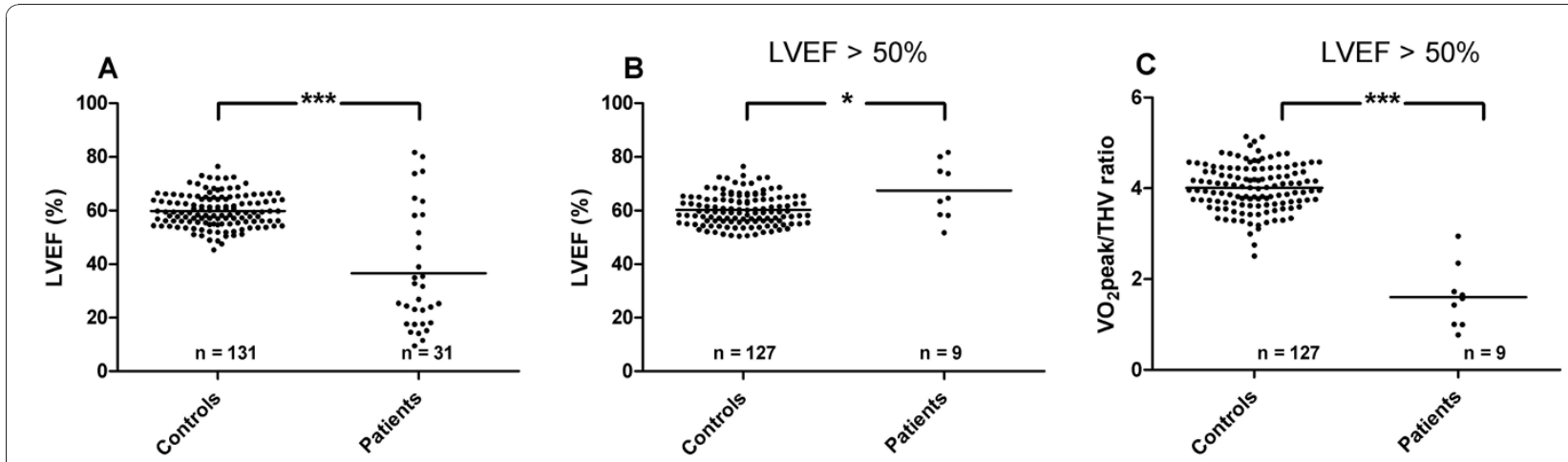

Figure 3 Left ventricular ejection fraction in relation to $\mathrm{VO}_{2}$ peak/THV ratio. Left ventricular ejection fraction (LVEF) for $\mathbf{A}$ ) all subjects and B) control subjects and heart failure patients with LVEF > 50\% and C) $\mathrm{VO}_{2}$ peak/THV ratio for the control subjects and heart failure patients with LVEF $>50 \%$. In the heart failure patients with LVEF $>50 \%$ there was a significantly lower $\mathrm{VO}_{2}$ peak $T H V$ ratio despite a slightly higher LVEF compared to the control subjects. The solid line represents the mean value. ${ }^{*} p<0.05$ and ${ }^{* * *} p<0.001$

vs $1309 \pm 430 \mathrm{ml} / \mathrm{min} ; \mathrm{p}<0.001)$. However, there was a considerable overlap between the two groups (Figure $5 \mathrm{~A}$ ). Ten control subjects and $10 \mathrm{HF}$ patients had overlapping $\mathrm{VO}_{2}$ peak (Figure $5 \mathrm{~B}$ ). The $\mathrm{VO}_{2}$ peak/THV ratio, however, differed significantly between these two groups ( $\mathrm{p}<$ 0.001) (Figure 5C). The LVEF for the overlapping healthy volunteers did not differ significantly from the overlapping HF patients $(42 \pm 25 \%$ vs $61 \pm 5 \%$; $p=0.11)$, whereas THV was significantly larger for the latter $(640$ \pm 66 vs $1092 \pm 336 \mathrm{ml} / \mathrm{min} ; \mathrm{p}<0.001)$.

In $68 \%(21 / 31)$ of the HF patients a pro-BNP was taken $11 \pm 25$ days from the exercise test. There was a significant correlation between decreasing $\mathrm{VO}_{2}$ peak/THV ratio and increasing pro-BNP $\left(\mathrm{r}^{2}=0.42, \mathrm{p}=0.002\right)$.
Furthermore, the $\mathrm{VO}_{2}$ peak/THV ratio was the only independent predictor of HF $(\mathrm{p}<0.001$; Table 2). The area under the curve (AUC) for the $\mathrm{VO}_{2}$ peak/THV ratio to diagnose HF was 1.0. With a cut-off value of 3.0, the $\mathrm{VO}_{2}$ peak/THV ratio had a sensitivity of $100 \%$ and a specificity of $97 \%$. Even though there was a slight decrease in $\mathrm{VO}_{2}$ peak/THV ratio with increasing age, there was a significant difference between patients and healthy volunteers for all age groups (Figure 6).

\section{Discussion}

This study shows that a $\mathrm{VO}_{2}$ peak/THV ratio can be used to distinguish patients with HF from healthy volunteers and athletes, even in patients with preserved
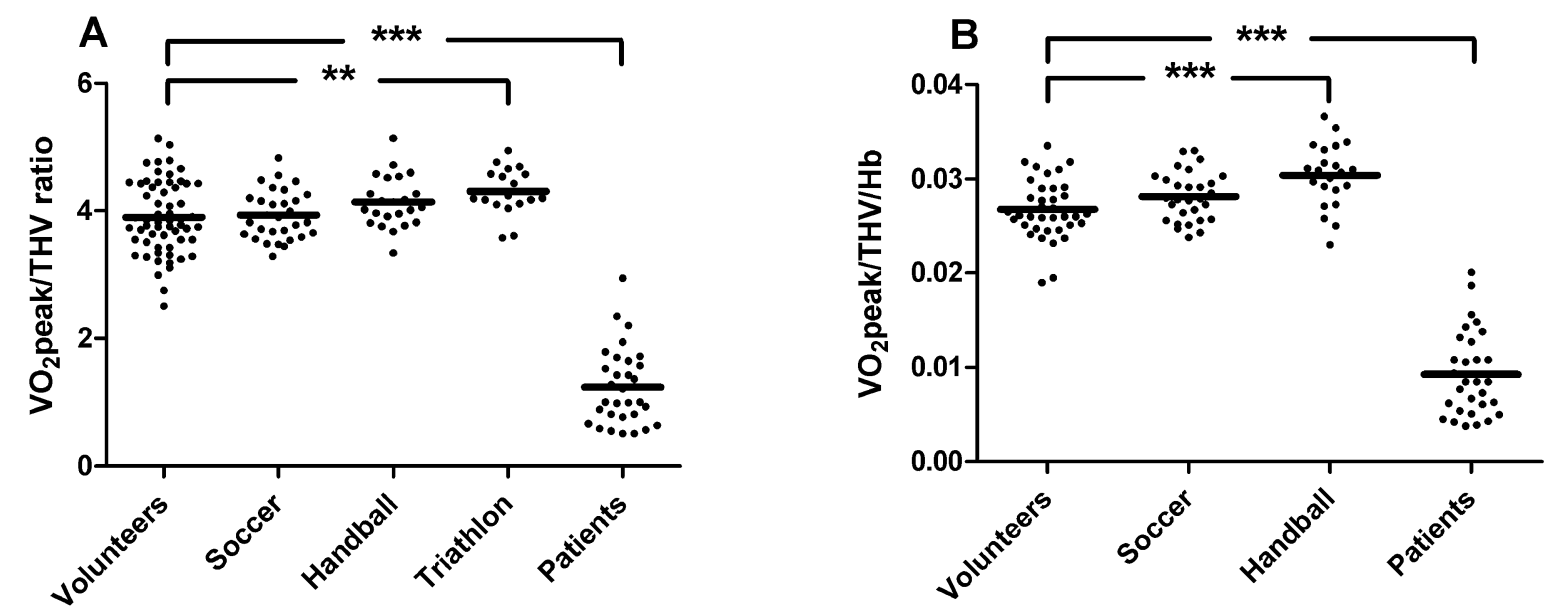

Figure $4 \mathrm{VO}_{2}$ peak/THV ratio in heart failure patients and control subjects. $\mathrm{VO}_{2}$ peak/THV ratio in heart failure patients compared to healthy volunteers and different groups of athletes. The $\mathrm{VO}_{2}$ peak/THV ratio was significantly lower in the heart failure patients compared to the control groups $(\mathbf{A})$. This relationship remained unchanged after normalizing the results to hemoglobin levels $(\mathbf{B})$. The solid line represents the mean value. ${ }^{* *} p<0.01$ and ${ }^{* *} p<0.001$ compared to healthy volunteers. 


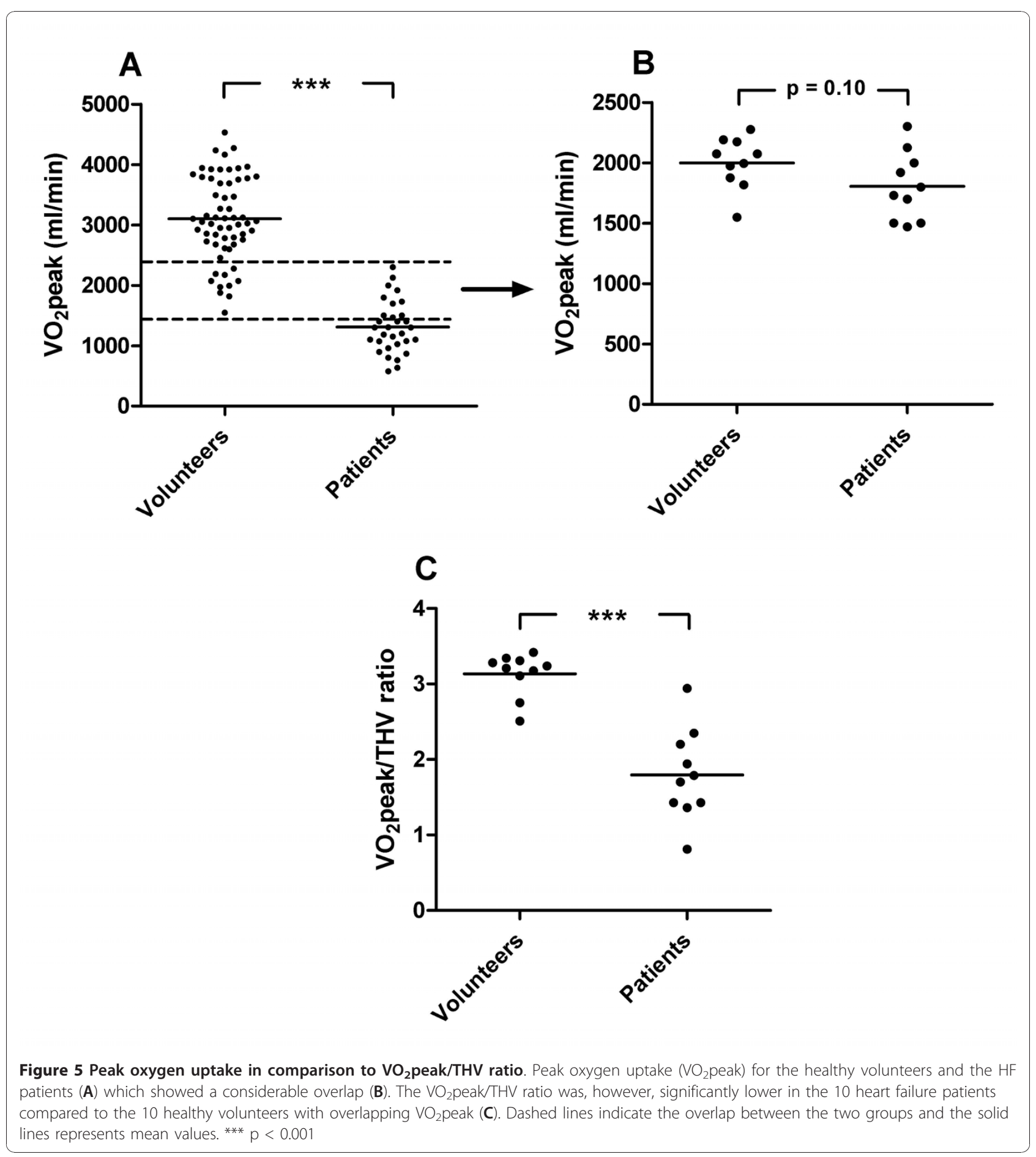

systolic LV function and after normalizing for hemoglobin levels.

\section{Clinical use of the proposed $\mathrm{VO}_{2}$ peak/THV ratio}

It is expected that the $\mathrm{VO}_{2}$ peak/THV ratio will drop in the presence of HF, since cardiac output, and consequently $\mathrm{VO}_{2}$ peak, is disproportional to the metabolic requirements of the peripheral tissue in the situation of a failing heart. However, when and in which stage of HF development the $\mathrm{VO}_{2}$ peak/THV ratio decreases is not known. A decreased $\mathrm{VO}_{2}$ peak/THV ratio could potentially be seen in patients with no symptoms at rest and in the absence of significant structural cardiac abnormalities. 
Table 2 Forward stepwise multivariate regression analysis for prediction of heart failure

\begin{tabular}{|c|c|c|}
\hline & Beta-value (r-value) & p-value \\
\hline $\mathrm{VO}_{2}$ peak/THV ratio & -0.90 & $<0.0001$ \\
\hline Excluded variables & Partial correlation & \\
\hline THV & 0.03 & 0.74 \\
\hline LVEDV & 0.05 & 0.53 \\
\hline LVEF & -0.10 & 0.23 \\
\hline $\mathrm{VO}_{2}$ peak $\left(\mathrm{ml} \mathrm{min}{ }^{-1}\right)$ & 0.03 & 0.74 \\
\hline $\mathrm{VO}_{2}$ peak $\left.\mathrm{kg}_{(\mathrm{ml} \mathrm{min}} \mathrm{m}^{-1} \mathrm{~kg}^{-1}\right)$ & -0.14 & 0.09 \\
\hline
\end{tabular}

LVEDV = left ventricular end-diastolic volume, LVEF $=$ left ventricular ejection fraction, $\mathrm{THV}=$ total heart volume, $\mathrm{VO}_{2}$ peak = peak oxygen uptake.

Currently, maximal exercise test with analysis of respiratory gases and analysis of $\mathrm{VO}_{2}$ peak is predominantly used in patients with terminal HF under consideration for heart transplantation [7]. The present study suggests that assessment of $\mathrm{VO}_{2}$ peak in relation to THV for determination of a $\mathrm{VO}_{2}$ peak/THV ratio can be of potential use even in non-terminal and early stage HF, maybe even before the patient exhibit symptoms, such as in stage A HF [4]. Another possible application of a $\mathrm{VO}_{2}$ peak/THV ratio is in management of patients with a history of endurance training and a sudden change in exercise capacity. These patients might perform within normal limits during a maximal exercise test with analysis of respiratory gases when compared to age and gender matched controls. However, in relation to THV the working capacity might be decreased which would be detected by a low $\mathrm{VO}_{2}$ peak/THV ratio as an indicator of early stage HF. This is supported by the findings that the healthy volunteers and the HF patients with overlapping $\mathrm{VO}_{2}$ peak showed a significant difference in

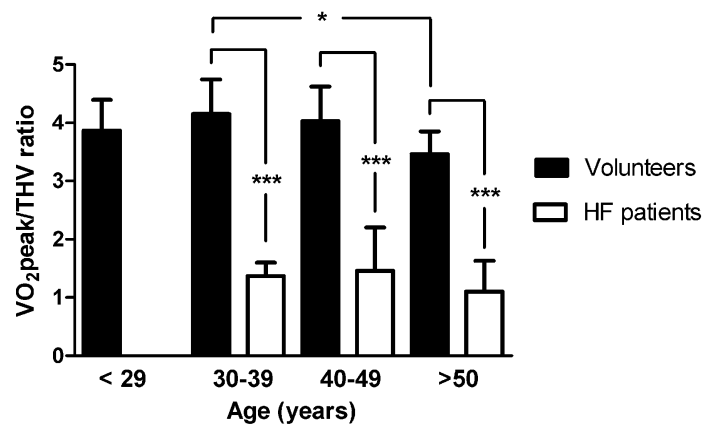

Figure $6 \mathrm{VO}_{2}$ peak/THV ratio in different age groups. $\mathrm{VO}_{2}$ peak/ $\mathrm{THV}$ ratio in healthy volunteers and in heart failure patients in different age groups. Even though there was a slight decrease in $\mathrm{VO}_{2}$ peak/THV ratio with increasing age in the healthy volunteers, $\mathrm{VO}_{2}$ peak/THV ratio remained significantly higher in the healthy volunteers compared to the heart failure patients. ${ }^{*} p<0.05$ and $* * * p<0.001$
$\mathrm{VO}_{2}$ peak/THV ratio with almost no overlap, indicating that the ratio has additional diagnostic value. Furthermore, LVEF was not statistically significant different between the two overlapping groups. Thus, $\mathrm{VO}_{2}$ peak/ THV provides diagnostic information beyond LVEF.

Even though there was a significant difference between control subjects and HF patients with regard to LVEF in the present study, almost $30 \%$ of the patients had normal LVEF. However, these patients had significantly lower $\mathrm{VO}_{2}$ peak/THV ratio than the control subjects with almost no overlap. Thus, $\mathrm{VO}_{2}$ peak/THV ratio may also be used as a marker of HF in patients with preserved systolic LV function.

Heart failure is often described based on clinical symptoms as being mild, moderate, or severe. Mild HF is used for patients with no significant physical limitations due to dyspnoea or fatigue and severe HF is used for patients who are markedly symptomatic with a need for frequent medical attention. Moderate HF is used for the remaining patients. For clinical management of HF patients and for randomized clinical trials, the New York Heart Association (NYHA) functional classification $[22,23]$ is often employed. However, the accuracy of diagnosing HF by clinical means alone is often inadequate $[2,3]$. Hence, there is a need for objective measures of cardiac performance in order to determine the efficiency of different therapeutic strategies in randomized clinical trials.

The clinical use a $\mathrm{VO}_{2}$ peak/THV ratio could potentially complement commonly used cardiac diagnostic biomarkers such as ECG and biochemical markers. A commonly used biochemical marker for severity of HF is pro-BNP, which has been shown to correlate with the severity of HF $[24,25]$. In the present study, the $\mathrm{VO}_{2}$ peak/THV ratio was shown to correlate with pro-BNP, indicating that the ratio can potentially serve as a measure for severity of HF.

\section{Normalization of peak oxygen uptake to cardiac dimension rather than body weight}

Lower limits for $\mathrm{VO}_{2}$ peak are usually determined in relation to body weight and used to determine if a patient is suitable for heart transplantation or not $[26,27]$. However, the present study show a considerable variability in $\mathrm{VO}_{2}$ peak for a given body weight (Figure $2 \mathrm{~B}$ ). Total heart volume, however, was shown to be closely correlated to $\mathrm{VO}_{2}$ peak in healthy volunteers and athletes but not in HF patients. Thus, for the non-failing heart, the $\mathrm{VO}_{2}$ peak/THV ratio is preserved in the presence of a physiologically enlarged heart, whereas for the failing heart the $\mathrm{VO}_{2}$ peak/THV ratio is not preserved as THV increases due to pathological enlargement of the heart. This suggests that $\mathrm{VO}_{2}$ peak should be normalized to THV and not to body weight. This is 
in line with a recent paper by Saltin et al [28] and experimental animal studies $[9,10]$ showing that $\mathrm{VO}_{2}$ peak is determined primarily by cardiac dimension and not peripheral factors such as the efficiency of oxygen uptake in peripheral tissue [29]. This is also supported by the present study showing that a $\mathrm{VO}_{2}$ peak/ THV ratio is significantly lower in HF compared to healthy volunteers and athletes even after normalizing for hemoglobin levels.

\section{Determination of total heart volume}

In the present study THV was determined by CMR, which is considered the gold standard for assessing cardiac dimensions and function [13]. In situations when CMR is not available or is contraindicated, i.e. in patients with biventricular pacing, THV could potentially also be determined by low dose-cardiac CT, preferably gated. However, non-gated examinations would also be possible if CT thorax is performed for other reasons, since THV varies little during the cardiac cycle $[15,17,18]$. Three dimensional echocardiography might potentially also be used to determine THV, although this technique may suffer from incomplete coverage of the tissue within the pericardium. By using the THV, enlargement of all cardiac chambers including the atria is considered. Enlargement of the left atrium has been shown to provide prognostic value in HF patients with normal LVEF [30].

\section{Limitations}

The results of the present study should be interpreted in the light of some limitations. The number of patients in the present study is limited and the patients were retrospectively included with clinically diagnosed HF and clinically determined etiology. Thus, no specific HF inclusion criteria based on biochemical markers, ECG or echocardiographic variables were applied. Furthermore, the patients had different etiologies and different stages of HF. However, this pilot study can be considered a proof of the concept study for determining a $\mathrm{VO}_{2}$ peak/ THV ratio as an objective measure of cardiac capacity, independent of HF etiology.

Due to symptoms during the exercise test, HF patients might not reach $\mathrm{VO}_{2}$ peak representative of the individual's actual maximal oxygen uptake capacity. For this reason $\mathrm{VO}_{2}$ peak is referred to as peak and not maximal oxygen uptake in the present study.

There was a significant difference in mean age between the patient population and the control groups. However, the slight decrease in $\mathrm{VO}_{2}$ peak/THV ratio found with increased age in the healthy volunteers (2165 years) is negligible compared to the decrease in $\mathrm{VO}_{2}$ peak/THV ratio found in the HF patients.
Since $\mathrm{VO}_{2}$ peak can not be obtained in HF patients with acute decompensation, the $\mathrm{VO}_{2}$ peak/THV ratio can not be used in these patients. The $\mathrm{VO}_{2}$ peak/THV ratio might, however, be of significant benefit when the HF diagnosis is uncertain, such as in the situation of stage A HF or if the progression of the disease is less clear.

Furthermore, the prognostic value of the $\mathrm{VO}_{2}$ peak/ THV ratio also remains to be determined in prospective follow-up studies of different patient groups with established HF or at risk for developing HF.

\section{Conclusions}

The $\mathrm{VO}_{2}$ peak/THV ratio can be used to distinguish patients with known HF from healthy volunteers and athletes, even in patients with preserved systolic LV function and after normalizing for hemoglobin levels.

\section{Acknowledgements}

We thank our technicians Ann-Helen Arvidsson and Christel Carlander for their invaluable assistance with data acquisition.

\section{Author details}

'Dept of Clinical Physiology, Lund University and Skåne University Hospital, Lund, Sweden. ${ }^{2}$ Dept of Sport Sciences, Malmö University, Malmö, Sweden. ${ }^{3}$ Dept of Cardiology, Lund University and Skåne University Hospital, Lund, Sweden.

\section{Authors' contributions}

$\mathrm{HE}, \mathrm{KS}, \mathrm{MC}$, and $\mathrm{HA}$ have made substantial contributions to conception and design of the study. $\mathrm{HE}, \mathrm{KS}, \mathrm{MC}, \mathrm{TB}, \mathrm{BE}, \mathrm{HM}$, and $\mathrm{BH}$, were responsible for acquisition of data. $\mathrm{HE}, \mathrm{KS}, \mathrm{MC}, \mathrm{BE}$, and $\mathrm{HA}$ were responsible for analysis and interpretation of the data. All authors have been involved in drafting the manuscript and revising it critically for important intellectual content. Furthermore, all authors have given final approval of the current version to be published.

\section{Competing interests}

The authors declare that they have no competing interests.

Received: 23 April 2010 Accepted: 16 December 2010

Published: 16 December 2010

\section{References}

1. Dickstein K, Cohen-Solal A, Filippatos G, McMurray JJ, Ponikowski P, PooleWilson PA, Stromberg A, van Veldhuisen DJ, Atar D, Hoes AW, Keren A, Mebazaa A, Nieminen M, Priori SG, Swedberg K, Vahanian A, Camm J, De Caterina R, Dean V, Dickstein K, Filippatos G, Funck-Brentano C, Hellemans I, Kristensen SD, McGregor K, Sechtem U, Silber S, Tendera M, Widimsky P, Zamorano JL: ESC Guidelines for the diagnosis and treatment of acute and chronic heart failure 2008: the Task Force for the Diagnosis and Treatment of Acute and Chronic Heart Failure 2008 of the European Society of Cardiology. Developed in collaboration with the Heart Failure Association of the ESC (HFA) and endorsed by the European Society of Intensive Care Medicine (ESICM). Eur Heart J 2008, 29(19):2388-442.

2. Wheeldon NM, MacDonald TM, Flucker CJ, McKendrick AD, McDevitt DG, Struthers AD: Echocardiography in chronic heart failure in the community. Q J Med 1993, 86(1):17-23.

3. Remes J, Lansimies E, Pyorala K: Usefulness of M-mode echocardiography in the diagnosis of heart failure. Cardiology 1991, 78(3):267-77.

4. Hunt SA: ACC/AHA 2005 guideline update for the diagnosis and management of chronic heart failure in the adult: a report of the American College of Cardiology/American Heart Association Task Force on Practice Guidelines (Writing Committee to Update the 2001 Guidelines for the Evaluation and Management of Heart Failure). J Am Coll Cardiol 2005, 46(6):e1-82. 
5. Ekblom B, Hermansen L: Cardiac output in athletes. J Appl Physiol 1968, 25(5):619-25.

6. Mitchell JH, Sproule BJ, Chapman CB: The physiological meaning of the maximal oxygen intake test. J Clin Invest 1958, 37(4):538-47.

7. Weber KT, Janicki JS, McElroy PA: Determination of aerobic capacity and the severity of chronic cardiac and circulatory failure. Circulation 1987, 76(6 Pt 2):V|40-5.

8. Weber KT, Janicki JS, Ward DM, McElroy PA: Measurement and interpretation of maximal oxygen uptake in patients with chronic cardiac or circulatory failure. J Clin Monit 1987, 3(1):31-7.

9. Hammond HK, White FC, Bhargava V, Shabetai R: Heart size and maximal cardiac output are limited by the pericardium. Am J Physiol 1992, 263(6 Pt 2):H1675-81.

10. Stray-Gundersen J, Musch TI, Haidet GC, Swain DP, Ordway GA, Mitchell JH: The effect of pericardiectomy on maximal oxygen consumption and maximal cardiac output in untrained dogs. Circ Res 1986, 58(4):523-30

11. Steding K, Engblom H, Buhre T, Carlsson M, Mosen H, Wohlfart B, Arheden $\mathrm{H}$ : Relation between cardiac dimensions and peak oxygen uptake. J Cardiovasc Magn Reson 12(1):8.

12. Weber KT, Clark WA, Janicki JS, Shroff SG: Physiologic versus pathologic hypertrophy and the pressure-overloaded myocardium. J Cardiovasc Pharmacol 1987, 10(Suppl 6):S37-50.

13. Pennell DJ, Sechtem UP, Higgins CB, Manning WJ, Pohost GM, Rademakers FE, van Rossum AC, Shaw LJ, Yucel EK: Clinical indications for cardiovascular magnetic resonance (CMR): Consensus Panel report. J Cardiovasc Magn Reson 2004, 6(4):727-65.

14. Simonetti OP, Kim RJ, Fieno DS, Hillenbrand HB, Wu E, Bundy JM, Finn JP, Judd RM: An improved MR imaging technique for the visualization of myocardial infarction. Radiology 2001, 218(1):215-23.

15. Carlsson M, Cain P, Holmqvist C, Stahlberg F, Lundback S, Arheden H: Total heart volume variation throughout the cardiac cycle in humans. Am J Physiol Heart Circ Physiol 2004, 287(1):H243-50.

16. Heiberg E, Sjogren J, Ugander M, Carlsson M, Engblom H, Arheden H: Design and validation of Segment-freely available software for cardiovascular image analysis. BMC Med Imaging 2010, 10:1.

17. Bowman AW, Kovacs SJ: Assessment and consequences of the constantvolume attribute of the four-chambered heart. Am J Physiol Heart Circ Physiol 2003, 285(5):H2027-33.

18. Waters EA, Bowman AW, Kovacs SJ: MRI-determined left ventricular "crescent effect": a consequence of the slight deviation of contents of the pericardial sack from the constant-volume state. Am J Physiol Heart Circ Physiol 2005, 288(2):H848-53.

19. Carlsson M, Ugander M, Mosen H, Buhre T, Arheden H: Atrioventricular plane displacement is the major contributor to left ventricular pumping in healthy adults, athletes, and patients with dilated cardiomyopathy. Am J Physiol Heart Circ Physiol 2007, 292(3):H1452-9.

20. Carlsson $M$, Ugander $M$, Heiberg $E$, Arheden $H$ : The quantitative relationship between longitudinal and radial function in left, right, and total heart pumping in humans. Am J Physiol Heart Circ Physiol 2007, 293(1):H636-44.

21. Carlsson M, Rosengren A, Ugander M, Ekelund U, Cain PA, Arheden H: Center of volume and total heart volume variation in healthy subjects and patients before and after coronary bypass surgery. Clin Physiol Funct Imaging 2005, 25(4):226-33.

22. AHA medical/scientific statement. 1994 revisions to classification of functional capacity and objective assessment of patients with diseases of the heart. Circulation 1994, 90(1):644-5.

23. Heart Failure Society of America (HFSA) practice guidelines. HFSA guidelines for management of patients with heart failure caused by left ventricular systolic dysfunction-pharmacological approaches. J Card Fail 1999, 5(4):357-82.

24. Mueller C, Scholer A, Laule-Kilian K, Martina B, Schindler C, Buser P, Pfisterer M, Perruchoud AP: Use of B-type natriuretic peptide in the evaluation and management of acute dyspnea. N Engl J Med 2004, 350(7):647-54.

25. Wright SP, Doughty RN, Pearl A, Gamble GD, Whalley GA, Walsh HJ, Gordon G, Bagg W, Oxenham H, Yandle T, Richards M, Sharpe N: Plasma amino-terminal pro-brain natriuretic peptide and accuracy of heartfailure diagnosis in primary care: a randomized, controlled trial. J Am Coll Cardiol 2003, 42(10):1793-800.

26. Costanzo MR, Augustine S, Bourge R, Bristow M, O'Connell JB, Driscoll D, Rose E: Selection and treatment of candidates for heart transplantation. A statement for health professionals from the Committee on Heart
Failure and Cardiac Transplantation of the Council on Clinical Cardiology, American Heart Association. Circulation 1995, 92(12):3593-612.

27. Mancini DM, Eisen H, Kussmaul W, Mull R, Edmunds LH, Wilson JR: Value of peak exercise oxygen consumption for optimal timing of cardiac transplantation in ambulatory patients with heart failure. Circulation 1991, 83(3):778-86.

28. Saltin B, Calbet JA: Point: in health and in a normoxic environment, VO2 max is limited primarily by cardiac output and locomotor muscle blood flow. J Appl Physiol 2006, 100(2):744-5.

29. Wagner PD: Counterpoint: in health and in normoxic environment VO2max is limited primarily by cardiac output and locomotor muscle blood flow. J Appl Physiol 2006, 100(2):745-8.

30. Rossi A, Cicoira M, Florea VG, Golia G, Florea ND, Khan AA, Murray ST, Nguyen JT, O'Callaghan P, Anand IS, Coats A, Zardini P, Vassanelli C, Henein M: Chronic heart failure with preserved left ventricular ejection fraction: diagnostic and prognostic value of left atrial size. Int J Cardiol 2006, 110(3):386-92.

doi:10.1186/1532-429X-12-74

Cite this article as: Engblom et al:. Peak oxygen uptake in relation to total heart volume discriminates heart failure patients from healthy volunteers and athletes. Journal of Cardiovascular Magnetic Resonance $201012: 74$.

\section{Submit your next manuscript to BioMed Central and take full advantage of:}

- Convenient online submission

- Thorough peer review

- No space constraints or color figure charges

- Immediate publication on acceptance

- Inclusion in PubMed, CAS, Scopus and Google Scholar

- Research which is freely available for redistribution 